\title{
The peritoneum at laparotomy: A survey of gynaecological practice among Nigerian gynaecologists
}

\author{
A A Bamigboye, ${ }^{1} \mathrm{MB} \mathrm{ChB}$, MMed, FCOG (SA), PhD; F O Okonofua, ${ }^{2} \mathrm{PhD}$, FAS \\ ${ }^{1}$ Faculty of Clinical Sciences, University of Medical Sciences, Ondo, Nigeria and School of Clinical Sciences, Department of Obstetrics and \\ Gynaecology, University of the Witwatersrand, Johannesburg, South Africa \\ ${ }^{2}$ Faculty of Clinical Sciences, University of Medical Sciences, Ondo, Nigeria
}

Corresponding author: A A Bamigboye (aabamig@gmail.com)

\begin{abstract}
Background. The debate on the benefit of leaving the peritoneum unsutured is ongoing among gynaecologists. There is yet to be a final decision on this surgical step, especially considering the long-term complications of adhesion formation, subfertility and chronic pelvic pain.

Objectives. The objective of the study is to determine the attitudes of Nigerian gynaecologists toward the peritoneum during laparotomy for both benign conditions and caesarean sections.

Methods. The survey was conducted during the 50th International Conference of Gynaecologists hosted by the Society of Gynaecology and Obstetrics of Nigeria in October 2015. A questionnaire was distributed to attending participants across the board regarding peritoneal closure at laparotomy. A total of 125 respondents completed the survey. Data were entered into SSPA statistical software for analysis.

Results. The attitude towards the peritoneum was not associated with the year of experience as a gynaecologist. The reasons for the decision not to close the peritoneum was mostly based on the little evidence there is as regards the benefits.

Conclusion. The attitude towards the peritoneum during gynaecological procedures amongst Nigerian specialists appears to be in congruity with international practices where there is no clear-cut preference on the status of the peritoneum. However, the younger specialists gravitate towards non-closure.

S Afr J Obstet Gynaecol 2017;23(2):48-50. DOI: 10.7196/SAJOG.2017.v23i2.1131
\end{abstract}

Surgeons in obstetrics and gynaecology have different approaches to the fate of the peritoneal membranes after they have been breached during laparotomy. Animal experiments had not shown any advantages in the wound strength when the peritoneum was sutured. If anything, there was an increase in adhesions formation when the peritoneum was surgically approximated ${ }^{[1-4]}$ In the last decade, in humans, evidence from earlier studies has shown short-term benefits with non-closure of the peritoneal surfaces ${ }^{[5]}$ but recent trials have questioned the practice without looking into the long-term sequelae. ${ }^{[6-8]}$ Many clinicians may have adopted a change in practice owing to extrapolations from animal studies and earlier clinical trials. However, a meta-analysis of clinical trials in a 2014 Cochrane review that included more recent reviews, questioned change in practice without looking at the long-term sequelae of non-closure. Notable advantages of non-closure of the peritoneum during caesarean section were shorter operative periods and shorter periods of hospitalisation, which effectively reduces the cost of operative procedures. The long-term complications of adhesion formation and chronic pelvic pain were not convincingly addressed in the analysed studies. ${ }^{[6]}$

An American study has confirmed the advantage of parietal peritoneal closure over non-closure in the prevention of adhesions, while leaving the visceral peritoneum unsutured; there was a 3 - 5-fold reduction in adhesion formation taking into cognisance many cofounding variables such as ethnicity, medical status, and infectious morbidity. ${ }^{[7]}$ Another trial showed decreased adhesion formation in the allocation group, where the parietal peritoneum and the rectus sheath were approximated. ${ }^{[8]}$ Therefore the debate as to whether to close the peritoneal surfaces or not may be resurfacing.
In a previous population survey among registered South African obstetricians and gynaecologists, many reasons were provided regarding their practices toward the integrity of the peritoneum. The motivation for closing the peritoneum included anatomical restoration, prevention of wound dehiscence, reducing haemorrhage and adhesion formation. ${ }^{[4]}$ This survey aimed to assess the attitudes towards and practices of peritoneal non-closure among a cohort of Nigerian obstetricians and gynaecologists attending the annual gynaecological conference marking the 50th anniversary of the society foundation in 2015.

\section{Methods}

A questionnaire was distributed among delegates attending the Society of Gynaecologists and Obstetrics of Nigeria 2015. The proforma, which was self-administered, asked about the baseline data and their attitude towards closure and non-closure of the peritoneum during caesarean section and laparotomy for benign conditions. Data were entered into Microsoft Excel and analysed using SPSS epidemiological software (IBM Corp., USA).

\section{Results}

Of the 150 questionnaires handed out to delegates during two conference plenary sessions, 125 doctors responded. The average age of the surgeons who completed the survey was (mean (standard deviation (SD)) 44.9 (8.1) years, of whom $74.7 \%$ were male, $84.7 \%$ were specialist gynaecologists, and $15.2 \%$ were registrars. Most respondents (68.8\%) had $0-10$ years' experience as specialists and $74.6 \%$ were practising at referral hospitals (Table 1 ). The mean (SD) 
number of caesarean sections performed by the surgeons was 3.25 (1.8) per week, while mean (SD) 2.02 (1.2) laparotomies were performed weekly for a benign condition. Forty-eight percent (48.3\%) stated that they would not close the peritoneum at all, or close the parietal peritoneum only when the visceral peritoneum prevented closure of the rectus sheath. The remaining specialists stated that they would close either one or both of the peritoneal membranes (Table 2). There was no association between the specialists' experience and their attitudes toward the closure of the peritoneum; $41.2 \%$ of specialists would not close the peritoneum in the 0 - 10 years group v. $41.9 \%$ in the $11-20$ years group.

There was no statistically significant association between attitude towards the peritoneum and status (specialist v. registrar) or level of practice (secondary- or tertiary-level) in both procedures of hysterectomy and caesarean sections.

\section{Discussion}

The attitudinal practice of Nigerian obstetricians and gynaecologists towards the closing of the peritoneum did not differ based on the number of years' experience as a specialist. The doctors tend to gravitate toward what was advised globally, i.e. to leave the peritoneum unsutured, ${ }^{[10]}$ and might indicate the influence of continuous medical education in the practice of obstetrics and gynaecology. A 2003 Cochrane review documented the short-term benefits of non-closure of the peritoneum and the National Institute for Health and Clinical Excellence, UK (NICE) guideline may have popularised non-closure. ${ }^{[5,10]}$ Since the long-term complications of adhesion formation, infertility, and chronic pain is not fully ascertained, we believe that the motivation to change their practices may be for financial reasons where, following non-closure of the peritoneum, there was a reduction in theatre time and reduction in the use of suture materials and hospital stay ${ }^{[5]}$ A study involving 144 women looked into the issue of peritoneal closure v. non-closure and assessed the long-term complications of dyspareunia, adhesions, constipation, and infertility. There was no difference in morbidity. ${ }^{[9]}$ A collaborative study published in 2016, CORONIS, observed $\sim 8100$ women during a 3 -year follow-up and did not find any difference in the occurrence of pelvic pain, dyspareunia, bowel obstruction, bladder surgery, infertility and ectopic pregnancy, whether the peritoneum was closed with sutures or not. ${ }^{[1]]}$ Perhaps a longer follow-up of the CORONIS study in future might give clinicians the final answer to the fate of the peritoneum. A paradigm shift in practice cannot be succinctly advocated until the possible chronic sequelae have been assessed in studies incorporating longer follow-up periods.

Our findings were in agreement with those of a similar study $y^{[4]}$ conducted among registered South African obstetricians and gynaecologists, which showed that there was no clear preference concerning peritoneal closure.

The result of a similar survey was published in 2016 among US gyneaecologists, where it was concluded that variation in surgical practice including attitude towards the peritoneum varies amongst practising gynaecologists, with no particular trend of one approach over the other. ${ }^{[12]}$

\section{Study limitation}

The study sample included delegates at SOGON 2015 only and therefore was not nationally representative.

\section{Conclusion}

The trend amongst the gynaecologists present at the SOGON regarding whether to leave or close the peritoneum has no particular preference. A multicentre trial has been conducted, and if anything, a worsened outcome with peritoneal non-closure or otherwise has not been found. A longer follow-up will be needed before a final change in practice could be advocated. However, the need to continue with medical education cannot be overemphasised as recommendations might change with time.

Table 1. Attitude of gynaecologists towards peritoneal closure during laparotomy $(N=124)$

\begin{tabular}{|c|c|c|c|c|c|}
\hline $\begin{array}{l}\text { Years of } \\
\text { experience as a } \\
\text { specialist }\end{array}$ & $\begin{array}{l}\text { I always close both VP } \\
\text { and PP, } n(\%)\end{array}$ & $\begin{array}{l}\text { I close only the VP, } \\
n(\%)\end{array}$ & $\begin{array}{l}\text { I close only the PP, } \\
n(\%)\end{array}$ & $\begin{array}{l}\text { I do not close the } \\
\text { peritoneum at all, } \\
n(\%)\end{array}$ & $\begin{array}{l}\text { I close only when the } \\
\text { omentum is in the way, } \\
n(\%)\end{array}$ \\
\hline $11-20$ & $10(32.3)$ & $4(12.9)$ & 0 & $13(41.9)$ & $4(12.9)$ \\
\hline $21-30$ & $2(66.7)$ & 0 & $1(20.0)$ & 0 & $1(20.0)$ \\
\hline Total & $26(24.1)$ & $26(24.1)$ & $11(10.2)$ & $48(44.4)$ & $11(10.2)$ \\
\hline
\end{tabular}

Table 2. Attitude of obstetricians towards peritoneal closure during caeserean section $(N=124)$

\begin{tabular}{|c|c|c|c|c|c|}
\hline $\begin{array}{l}\text { Years of experience as } \\
\text { a specialist }\end{array}$ & $\begin{array}{l}\text { I always close both VP } \\
\text { and PP, } n(\%)\end{array}$ & $\begin{array}{l}\text { I close only the VP, } \\
n(\%)\end{array}$ & $\begin{array}{l}\text { I close only the PP, } \\
n(\%)\end{array}$ & $\begin{array}{l}\text { I do not close the } \\
\text { peritoneum at all, } \\
n(\%)\end{array}$ & $\begin{array}{l}\text { I close only when } \\
\text { the omentum is in } \\
\text { the way, } n(\%)\end{array}$ \\
\hline $0-10$ & $14(16.3)$ & $23(25.7)$ & $6(7.0)$ & $35(40.7)$ & $8(9.3)$ \\
\hline $11-20$ & $10(32.3)$ & 4 (12.9) & 1 (1.16) & 0 & $4(12.9)$ \\
\hline $21-30$ & $4(80.0)$ & 0 & 0 & $12(38.7)$ & 0 \\
\hline Total & $28(22.2)$ & $28(22.2)$ & $7(5.65)$ & $47(37.3)$ & $12(9.52)$ \\
\hline
\end{tabular}




\section{RESEARCH}

Acknowledgements. We acknowledge the statistical analysis done by $\mathrm{Mr} \mathrm{W}$ Oshuntokun of the Registry Department of the University of Medical Sciences, Ondo and Louismed Hospital, Lagos, for sponsoring the logistics. We equally mention Prof. FO Okonofua, Vice Chancellor and an Obstetrics and Gynecology researcher of the same university for his interest in the survey.

Author contributions. AB conceived the idea, planned the research, distributed and administered it, and wrote the body of the research, FO read and distributed the questionnaire and perused the draft report.

Funding. LouisMed Specialist Hospital, Lekki, Lagos, Nigeria.

\section{Conflicts of interest. None.}

1. Parulkar BG, Supe AN, Vora IM, Mathur SK. Effect of experimental nonclosure of peritoneum on development of suture line adhesions and wound strength in dogs. Indian J Gastroenterol 1986;5(4):251.

2. Kapur ML, Daneshwar A, Chopra P. Evaluation of peritoneal closure at laparotomy. Am J Surg 1979;137(5):650-652. https://doi.org/10.1016/0002-9610(79)90040-0

3. Kyzer S, Bayer I, Turani $\mathrm{H}$, Chaimoff $\mathrm{C}$. The influence of peritoneal closure on the formation of intraperitoneal adhesions: An experimental study. Int J Tissue React 1986;8(5):355-359.
4. Bamigboye AA, Buchman E, Hofmeyr GJ. Closure of peritoneum at laparotomy: A survey of gynecological practice. S Afr Med J 1999;89(3):332-335.

5. Bamigboye AA, Hofmeyr GJ. Closure versus non-closure of the peritoneum at caesarean section Cochrane Database Syst Rev 2003;4:CD000163. https://doi.org/10.1002/14651858.CD000163.

6. Bamigboye AA, Hofmeyr GJ. Closure versus non-closure of the peritoneum at caesarean section Short- and long-term outcomes. Cochrane Database Syst Rev 2014;8:CD000163. https://doi org/10.1002/14651858.CD000163.pub2 .

7. Lyell DJ, Caughey AB, Hu E, Daniels K. (2005). Peritoneal closure at primary cesarean delivery and adhesions. Obstet Gynecol 2005;106(2):275-280, https://doi.org/10.1097/01. AOG.0000171120.81732.4

8. Hamel KJ. Incidence of adhesions at repeat cesarean delivery. Am J Obstet Gynecol 2007;196(5):e31 e32. https://doi.org/10.1016/j.ajog.2006.09.011

9. Roset E, Boulvain M, Irion O. Nonclosure of the peritoneum during caesarean section: Long-term follow-up of a randomised controlled trial. Eur J Obstet Gynaecol Reprod Biol 2002;108:40-44. https://doi.org/10.1016/S0301-2115(02)00366-4

10. National Institute for Health and Clinical Excellence (NICE). Caesarean Section Guideline CG13. London: NICE, 2004.

11. The CORONIS collaborative group. Caesarean section surgical techniques: 3 year follow-up of the CORONIS fractional, factorial, unmasked, randomised controlled trial. Lancet 2016;388(10039):62 72. https://doi.org/10.1016/S0140-6736(16)00204-X

12. Lyell DJ, Power M, Murtough K, Ness A, et al. Surgical techniques at cesarean delivery: A US survey Surg J 2016;2(4):e119-e125. https://doi.org/10.1055/s-0036-1594247 